\title{
PENGGUNAAN WATER HEATING PADA MESIN PENGKONDISIAN UDARA SEBAGAI ALAT PENGENDALI KELEMBABAN UDARA DI DALAM RUANG OPERASI DI RUMAH SAKIT
}

\author{
Wardoyo \\ Teknik Mesin \\ Universitas Proklamasi 45 \\ Jalan Proklamasi No. 1 Babarsari, Depok, Yogyakarta
}

\begin{abstract}
This research was aimed to observe the performance of water heating as an air moisture controller device in a hospital surgery room.

The way the research was outside air in 27 degrees until 30 degrees celcius and moisture of 60 until 70 percent made suitable with requirement conditions determined for surgery room in the hospital i.e. 19 until 24 degrees celcius and moisture of 45 until 60 percent. To make that condition, the surgery room was equipped with air conditioner machine and water heating as an air moisture controller device. Hot water was circulated in water heating and air moisture was measured by a hygrometer.

Out of this research it obtained: measuring moisture value higher than theoretic moisture value. Calorie volume in water heating increased with water volume that was constant so that water heating could control air moisture.

There was a suitability in an air moisture ratio and calorie volume in water heating so that air moisture in surgery room could be measured as requirements.
\end{abstract}

Keywords : water heating, air moisture

\section{Abstrak}

Tujuan penelitian ini adalah mengamati kinerja water heating sebagai alat pengendali kelembaban udara di dalam ruang operasi rumah sakit.

Cara penelitian yaitu udara luar pada suhu 27 sampai dengan 30 derajat celcius dan kandungan kelembaban 60 sampai 70 persen dibuat sesuai dengan kondisi persyaratan yang ditentukan untuk ruang operasi di rumah sakit yaitu suhu 19 sampai 24 derajat celcius dan kelembabannya 45 sampai dengan 60 persen. Untuk membuat kondisi tersebut ruang operasi dilengkapi mesin pengkondisian udara dan water heating sebagai alat pengendali kelembaban udara. Air panas disirkulasikan pada water heating dan kelembaban udara diukur dengan hygrometer.

Dari penelitian ini didapatkan antara lain: nilai kelembaban pengukuran lebih tinggi dari nilai kelembaban teoritis. Jumlah kalor pada water heating meningkat dengan volume air yang konstan maka water heating dapat mengendalikan kelembaban udara.

Rasio kelembaban udara ada kesesuaian dengan jumlah kalor pada water heating sehingga kelembaban udara di ruang operasi dapat diatur sesuai persyaratan. 
Kata kunci: water heating, kelembaban udara

\section{Pendahuluan}

Kesegaran udara banyak dibutuhkan oleh setiap orang dalam kehidupan sehari-hari, baik kesegaran udara di dalam ruang maupun kesegaran udara di luar ruang. Untuk membuat kesegaran udara di dalam ruang digunakan mesin pengkondisian udara. Mesin pengkondisian udara disebut juga mesin refrigerator yaitu mesin yang menggunakan refrigran sebagai fluida kerjanya.

Penelitian ini kajiannya adalah penggunaan water heating pada mesin pengkondisian udara sebagai alat pengendali kelembaban udara di dalam ruang operasi di rumah sakit. Water heating merupakan suatu proses memanaskan udara yang dapat mencapai suhu dan kelembaban yang diinginkan/ dipersyaratkan. Penelitian dilakukan dengan menggunakan air panas yang disirkulasikan dan kelembaban udara diukur dengan hygrometer.

\section{Metode Penelitian}

Penelitian ini dilakukan di rumah sakit Dr. Sarjito Yogyakarta. Adapun bahan dan alat sebagai berikut.

\section{Bahan} atm.

Bahan yang digunakan adalah udara luar suhu $27^{\circ}$ sampai dengan $30^{\circ} \mathrm{C}$ dan tekanan 1

\section{Alat}

Alat yang digunakan adalah water heating seperti pada Gambar 1. Type water heating

- Ukuran : $285 \times 198 \times 20$

- Kontraksi :

$>$ pipa tembaga $\varnothing 0,5$

$>$ alur tembaga $33 \mathrm{bh}$

$>$ kisi-kisi alumunium $0,1 \mathrm{~mm}$

$>$ body galvanis plat

- Bahan water heating

- Air putih yang diproses dengan pemanasan dari discharge kompresor.

- Pemakaian water heating

- Berfungsi untuk mengendalikan kelembaban udara

Berikut ini gambar water heating yang digunakan dalam penelitian.

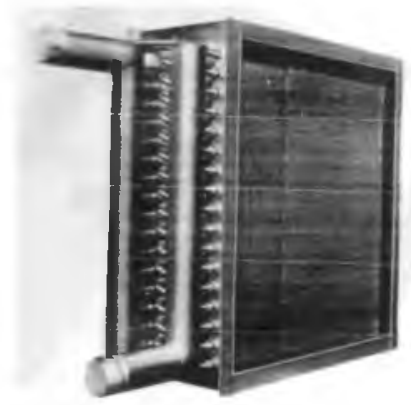

Gambar 1. Alat Sirkulasi Water Heating 


\section{Cara Penelitian}

Cara penelitian meliputi antara lain :

A. Persiapan Penelitian

Sebelum melaksanakan penelitian terlebih dahulu melakukan persiapan yaitu dengan mengecek semua komponen alat yang dipakai untuk penelitian termasuk alat-alat ukur yang digunakan.

B. Pelaksanaan Penelitian

Berikut ini gambar instalasi alat penelitian :

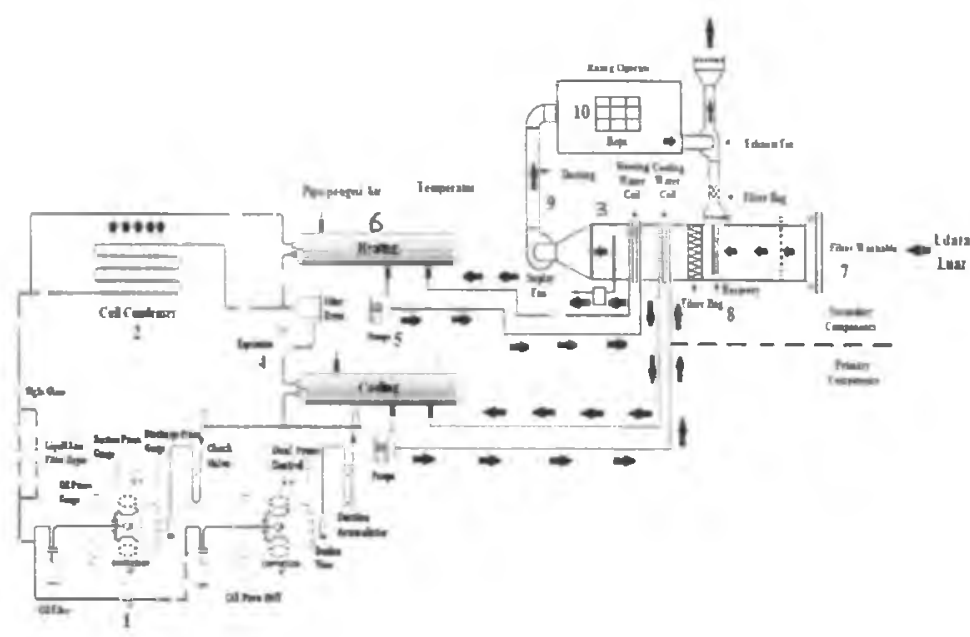

Gambar 2. Skema Instalasi Alat Penelitian

Keterangan gambar:

1. Kompresor

2. Coil kondesor

3. Coil water heating

4. Expansi

5. Pompa sirkulasi

6. Water heating

7. Filter udara luar
8. Recovery

9. Fan supply

10. Ruang operasi

11. Water cooling

12. Evaporator cooling

13. Pompa sirkulasi water cooling

Cara kerja instalasi alat penelitian

Udara luar pada temperatur $27^{\circ} \mathrm{C}-30^{\circ} \mathrm{C}$ dengan kandungan kelembaban $60 \%$ sampai $70 \%$. Untuk memenuhi persyaratan bahwa suhu dan kelembaban pada ruang operasi di rumah sakit dengan standar yang telah ditentukan yaitu suhu $19^{\circ} \mathrm{C}-24^{\circ} \mathrm{C}$ kelembaban $45 \%$ sampai $60 \%$. Untuk membuat kondisi tersebut, maka dilengkapi dengan air conditioner dan pengendalian kelembabannya dengan sistem water heating. Melalui proses sebagai berikut: 1.Compresor bekerja dengan siklus refrigerasi, proses discharge menekan panas. 2. Coil kondensor panasnya dihisap blower dibantu dengan udara bebas, sebagian panas disalurkan. 3. Water heating diatur sistem automatic dengan suhu $35^{\circ} \mathrm{C} \mathrm{On}$, suhu $50^{\circ} \mathrm{C}$ Off, disirkulasikan menggunakan 5. pompa coil water heating AHU disini terjadi proses pencampuran udara luar 
water cooler dan udara recovery \pm suhu $24^{\circ} \mathrm{C}$ melalui filter udara yang disusun ketiga main filter supply, exhause free filter return 9. Supplay blower fan 10. ke ruangan operasi dengan melalui hepa filter suhu $19^{\circ} \mathrm{C}-24^{\circ} \mathrm{C}$ kelembaban tercapai $45 \%-60 \%$, kondisi normal dan memenuhi standar tata udara ruang operasi.

\section{Hasil Penelitian Dan Pembahasan}

\subsection{Data Hasil Penelitian}

Berdasarkan hasil penelitian maka dapat dibuat tabel data sebagai berikut :

A. Data Ruang Operasi I

Tabel 1. Data Pengamatan Ruang Operasi I

\begin{tabular}{|l|c|c|c|}
\hline \multicolumn{1}{|c|}{ Waktu } & Suhu Ruang & Tekanan Udara Ruang & Kelembaban \\
\hline $\begin{array}{l}\text { Pagi } \\
06.00-10.00\end{array}$ & $22^{\circ} \mathrm{C}$ & $1 \mathrm{~K} . P a$ & $73 \%$ \\
\hline $\begin{array}{l}\text { Siang } \\
11.00-15.00\end{array}$ & $22^{\circ} \mathrm{C}$ & $1 / 2 \mathrm{~K} . P a$ & $71 \%$ \\
\hline $\begin{array}{l}\text { Sore } \\
16.00-18.00\end{array}$ & $22^{\circ} \mathrm{C}$ & $1 \frac{1}{2} \mathrm{~K} . P a$ & $73 \%$ \\
\hline $\begin{array}{l}\text { Malam } \\
19.00-22.00\end{array}$ & $22^{\circ} \mathrm{C}$ & $1 / 2 \mathrm{~K} \cdot \mathrm{Pa}$ & $72 \%$ \\
\hline
\end{tabular}

(Sumber : Ruang Operasi R.S Dr. Sardjito)

Data Penelitian Water Heating I

Tabel 2. Data Pengamatan Water Heating I

\begin{tabular}{|l|c|c|c|}
\hline \multicolumn{1}{|c|}{ Waktu } & Temperatur Air & Tekanan Air & Kalor (Panas) \\
\hline $\begin{array}{l}\text { Pagi } \\
06.00-10.00\end{array}$ & $38^{\circ} \mathrm{C} / 22^{\circ} \mathrm{C}$ & 2,3 bar & 1200 watt \\
\hline $\begin{array}{l}\text { Siang } \\
11.00-15.00\end{array}$ & $40^{\circ} \mathrm{C} / 22^{\circ} \mathrm{C}$ & 3,4 bar & 1350 watt \\
\hline $\begin{array}{l}\text { Sore } \\
16.00-18.00\end{array}$ & $43^{\circ} \mathrm{C} / 24^{\circ} \mathrm{C}$ & 3,6 bar & 1575 watt \\
\hline $\begin{array}{l}\text { Malam } \\
19.00-22.00\end{array}$ & $41^{\circ} \mathrm{C} / 23,5^{\circ} \mathrm{C}$ & 3,6 bar & 1462 watt \\
\hline
\end{tabular}

(Sumber : Ruang Operasi R.S Dr. Sardjito)

Data Ruang Operasi II

Tabel 3. Data Pengamatan Ruang Operasi II

\begin{tabular}{|l|c|c|c|}
\hline \multicolumn{1}{|c|}{ Waktu } & Suhu Ruang & Tekanan Udara Ruang & Kelembaban \\
\hline $\begin{array}{l}\text { PAGI } \\
06.00-10.00\end{array}$ & $21^{\circ} \mathrm{C}$ & $1 \mathrm{~K} . P a$ & $72 \%$ \\
\hline $\begin{array}{l}\text { SIANG } \\
11.00-15.00\end{array}$ & $23^{\circ} \mathrm{C}$ & $1 \mathrm{~K} . P a$ & $71 \%$ \\
\hline $\begin{array}{l}\text { SORE } \\
16.00-18.00\end{array}$ & $24^{\circ} \mathrm{C}$ & $1 / 2 \mathrm{~K} . P a$ & $69 \%$ \\
\hline $\begin{array}{l}\text { MALAM } \\
19.00-22.00\end{array}$ & $23^{\circ} \mathrm{C}$ & $1 \mathrm{~K} . P a$ & $69 \%$ \\
\hline
\end{tabular}

(Sumber : Ruang Operasi R.S Dr. Sardjito) 
Data Penelitian Water Heating II

Tabel 4. Data Pengamatan Water Heating II

\begin{tabular}{|l|c|c|c|}
\hline \multicolumn{1}{|c|}{ Waktu } & Temperatur Air & Tekanan Air & Kalor (Panas) \\
\hline $\begin{array}{l}\text { Pagi } \\
06.00-10.00\end{array}$ & $45^{\circ} \mathrm{C} / 22^{\circ} \mathrm{C}$ & 3,6 bar & 1687 watt \\
\hline $\begin{array}{l}\text { Siang } \\
11.00-15.00\end{array}$ & $47^{\circ} \mathrm{C} / 22^{\circ} \mathrm{C}$ & 3,5 bar & 1875 watt \\
\hline $\begin{array}{l}\text { Sore } \\
16.00-18.00\end{array}$ & $46,5^{\circ} \mathrm{C} / 23,5^{\circ} \mathrm{C}$ & 3,3 bar & 1725 watt \\
\hline $\begin{array}{l}\text { Malam } \\
19.00-22.00\end{array}$ & $45,5^{\circ} \mathrm{C} / 23^{\circ} \mathrm{C}$ & 3,2 bar & 1687 watt \\
\hline
\end{tabular}

(Sumber : Ruang Operasi R.S Dr. Sardjito)

Data Ruang Operasi III

Tabel 5. Data Pengamatan Ruang Operasi III

\begin{tabular}{|l|c|c|c|}
\hline \multicolumn{1}{|c|}{ Waktu } & Suhu Ruang & Tekanan Udara Ruang & Kelembaban \\
\hline $\begin{array}{l}\text { Pagi } \\
06.00-10.00\end{array}$ & $21^{\circ} \mathrm{C}$ & $1 \mathrm{~K} . P a$ & $72 \%$ \\
\hline $\begin{array}{l}\text { Siang } \\
11.00-15.00\end{array}$ & $22,5^{\circ} \mathrm{C}$ & $1 / 2 \mathrm{~K} . P a$ & $71 \%$ \\
\hline $\begin{array}{l}\text { Sore } \\
16.00-18.00\end{array}$ & $23,5^{\circ} \mathrm{C}$ & $11 / 2 \mathrm{~K} . P a$ & $70 \%$ \\
\hline $\begin{array}{l}\text { Malam } \\
19.00-22.00\end{array}$ & $23^{\circ} \mathrm{C}$ & $1 / 2 \mathrm{~K} . P a$ & $68 \%$ \\
\hline
\end{tabular}

(Sumber : Ruang Operasi R.S Dr. Sardjito)

Data Penelitian Water Heating III

Tabel 6. Data Pengamatan Water Heating III

\begin{tabular}{|l|c|c|c|}
\hline \multicolumn{1}{|c|}{ Waktu } & Temperatur Air & Tekanan Air & Kalor (Panas) \\
\hline $\begin{array}{l}\text { Pagi } \\
06.00-10.00\end{array}$ & $43^{\circ} \mathrm{C} / 22^{\circ} \mathrm{C}$ & 3,4 bar & 1575 watt \\
\hline $\begin{array}{l}\text { Siang } \\
11.00-15.00\end{array}$ & $46,5^{\circ} \mathrm{C} / 22^{\circ} \mathrm{C}$ & 3,3 bar & 1837 watt \\
\hline $\begin{array}{l}\text { Sore } \\
16.00-18.00\end{array}$ & $46^{\circ} \mathrm{C} / 22,5^{\circ} \mathrm{C}$ & 3,3 bar & 1762 watt \\
\hline $\begin{array}{l}\text { Malam } \\
19.00-22.00\end{array}$ & $45^{\circ} \mathrm{C} / 23^{\circ} \mathrm{C}$ & 3,2 bar & 1650 watt \\
\hline
\end{tabular}

(Sumber : Ruang Operasi R.S Dr. Sardjito)

B. Persamaan-persamaan yang digunakan untuk perhitungan (pengolahan) data hasil penelitian antara lain :

1. Kelembaban Relatif Teoritis (Qr) pada temperatur yang sama 
Qr $=\frac{\text { Kelembaban mutlak udara lembab }}{\text { Kelembaban mutlak udara jenuh }} \times 100 \%$

2. Rasio Kelembaban (W)

$W=0,622 \frac{\mathrm{P}_{\mathrm{s}}}{\mathrm{P}_{\mathrm{i}}-\mathrm{P}_{5}}$

Dengan $\quad P_{5}=$ Tekanan parsial uap air dalam keadaan jenuh.

$\mathrm{P}_{\mathrm{i}}=\mathrm{P}_{\mathrm{a}}+\mathrm{P}_{5}$

$\mathrm{P}_{\mathrm{a}}=$ Tekanan udara luar (1 atmosfir)

3. Jumlah Kalor (Q) pada Water Heating

$\mathrm{Q}=\mathrm{U} \cdot \mathrm{A} \cdot \Delta \mathrm{T}$

$\mathrm{A}=\pi \mathrm{D} \cdot \mathrm{L}$

Dengan $\mathrm{U}=$ koefisien perpindahan kalor konveksi menyeluruh
A $\quad=$ luas penampang pipa water heating
$\mathrm{D} \quad=$ diameter pipa water heating
$\mathrm{L} \quad=$ panjang pipa water heating
$\Delta \mathrm{T} \quad=$ perbedaan temperatur

Dari hasil perhitungan dapat dibuat grafik untuk membuat pembahasan antara

1. Grafik perbandingan kelembaban pengukuran dengan kelembaban teoritis.

Tabel 7. Perbandingan kelembaban pengukuran dengan kelembaban teoritis.

\begin{tabular}{|c|c|c|}
\hline No & Teoritis & Pengukuran \\
\hline 1. & $38.36 \%$ & $73 \%$ \\
2. & $15.50 \%$ & $71 \%$ \\
3. & $17.8 \%$ & $73 \%$ \\
4. & $30.56 \%$ & $72 \%$ \\
\hline
\end{tabular}

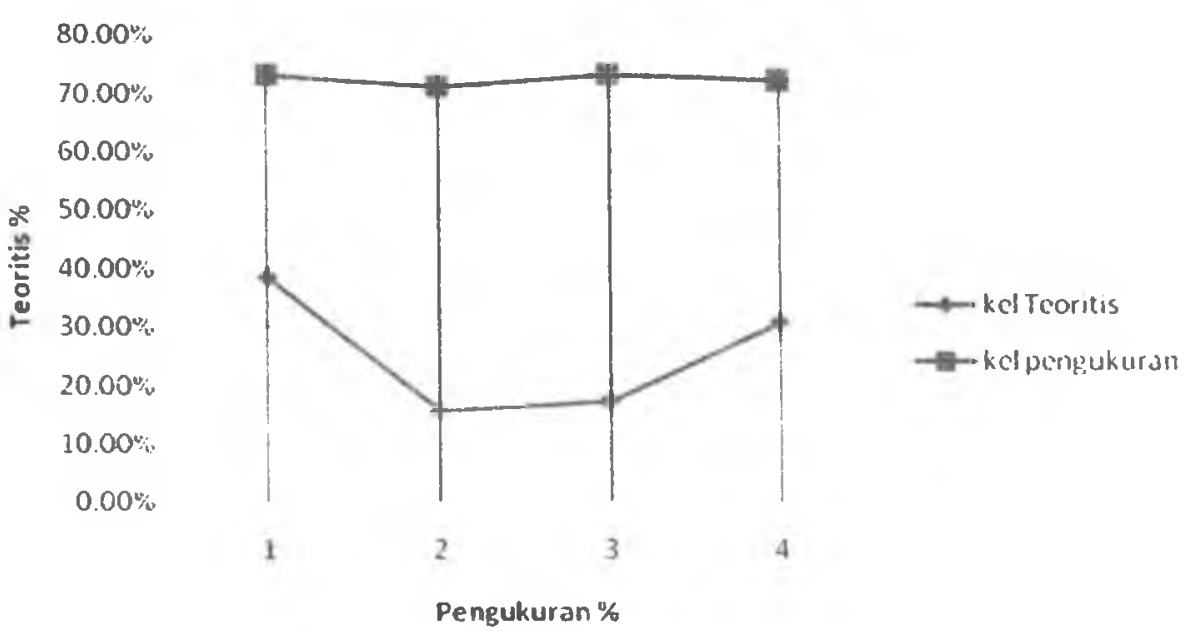

Gambar 3. Perbandingan kelembaban pengukuran dengan kelembaban teoritis.

Dari gambar grafik perbandingan antara kelembaban teoritis dan kelembaban pengukuran ada perbedaan prosentase total kelembaban, hal ini kelembaban teoritis lebih 
rendah jika dibanding dengan kelembaban pengukuran, ini disebabkan adanya kemungkinan faktor yang tidak diperhitungkan.

2. Grafik hubungan antara kelembaban terukur (Øp) dengan rasio kelembaban (W)

Tabel 8. Hubungan antara kelembaban pengukuran (Øp) dengan rasio kelembaban (W)

\begin{tabular}{|c|c|c|}
\hline No & $\varnothing \mathrm{P}$ & W \\
\hline 1. & $73 \%$ & 0.00566 \\
2. & $71 \%$ & 0.00308 \\
3. & $73 \%$ & 0.00924 \\
4. & $72 \%$ & 0.00308 \\
\hline
\end{tabular}

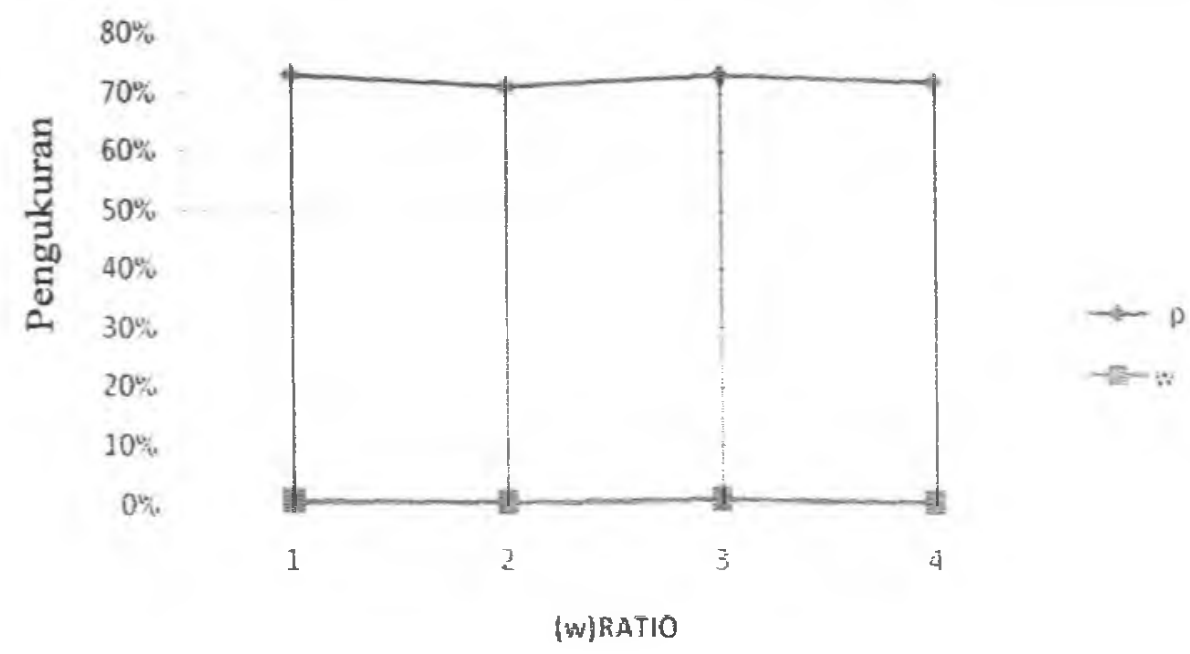

Gambar 4. Hubungan antara kelembaban pengukuran (Øp) dengan rasio kelembaban (W)

Dari grafik ini kelembaban pengukuran dengan rasio kelembaban ada kesesuaian karena ada pengaruh jumlah kalor yang sama dari Water Heating sehingga kelembaban udara di ruang operasi dapat diatur sesuai yang diinginkan.

3. Grafik hubungan antara kalor $(Q)$ dengan kelembaban terukur (Øp)

Tabel 9. Hubungan antara kalor (Q) dengan kelembaban terukur (Øp)

\begin{tabular}{|c|c|c|}
\hline No & $\mathrm{Q}(\mathrm{kw})$ & $\varnothing \mathrm{P}$ \\
\hline 1. & 1200 & 0,73 \\
2. & 1350 & 0,71 \\
3. & 1425 & 0,73 \\
4. & 1462 & 0,77 \\
\hline
\end{tabular}




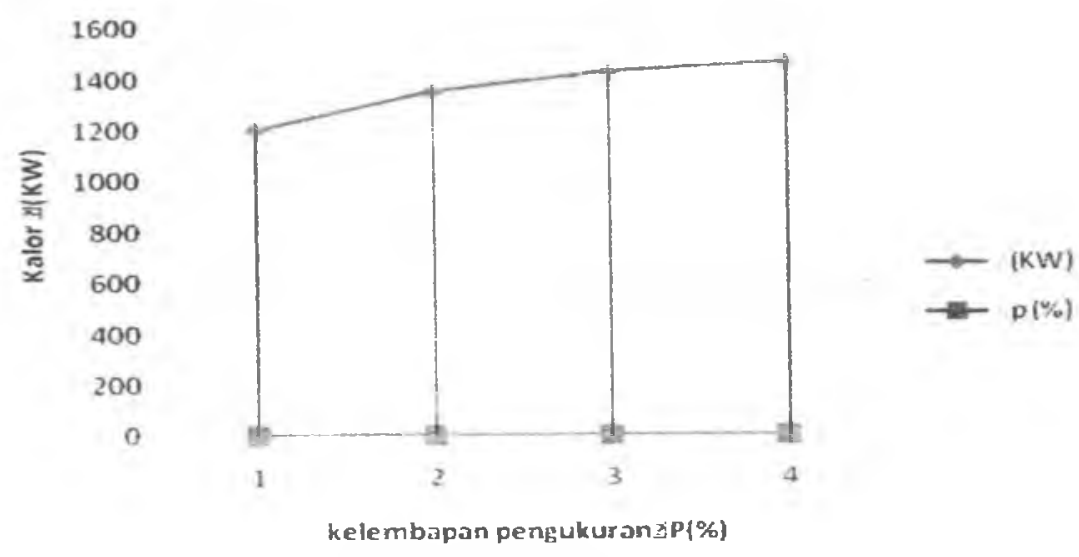

Gambar 5. Hubungan antara kalor (Q) dengan kelembaban terukur (Øp)

Dari grafik hubungan antara kalor dengan kelembaban pengukuran. Terlihat dengan meningkatnya jumlah kalor yang ditransfer diiringi dengan harga persentase kelembaban yang sama besarnya, hal ini berarti jumlah kalor dapat mengendalikan laju kelembaban.

4. Grafik hubungan antara kalor (Q) dengan uap jenuh air

Tabel 10. Hubungan antara kalor $Q$ dengan uap jenuh air

\begin{tabular}{|c|c|c|c|}
\hline No & Q (kw) & Uap jenuh $\mathrm{g} / \mathrm{m}^{3}$ & $\mathrm{~T}\left(\mathrm{C}^{\circ}\right)$ \\
\hline 1. & 1200 & 17.3 & $22{ }^{\circ} \mathrm{C}$ \\
2. & 1350 & 17.3 & $22{ }^{\circ} \mathrm{C}$ \\
3. & 1425 & 17.3 & $22{ }^{\circ} \mathrm{C}$ \\
4. & 1462 & 17.3 & $22{ }^{\circ} \mathrm{C}$ \\
\hline
\end{tabular}

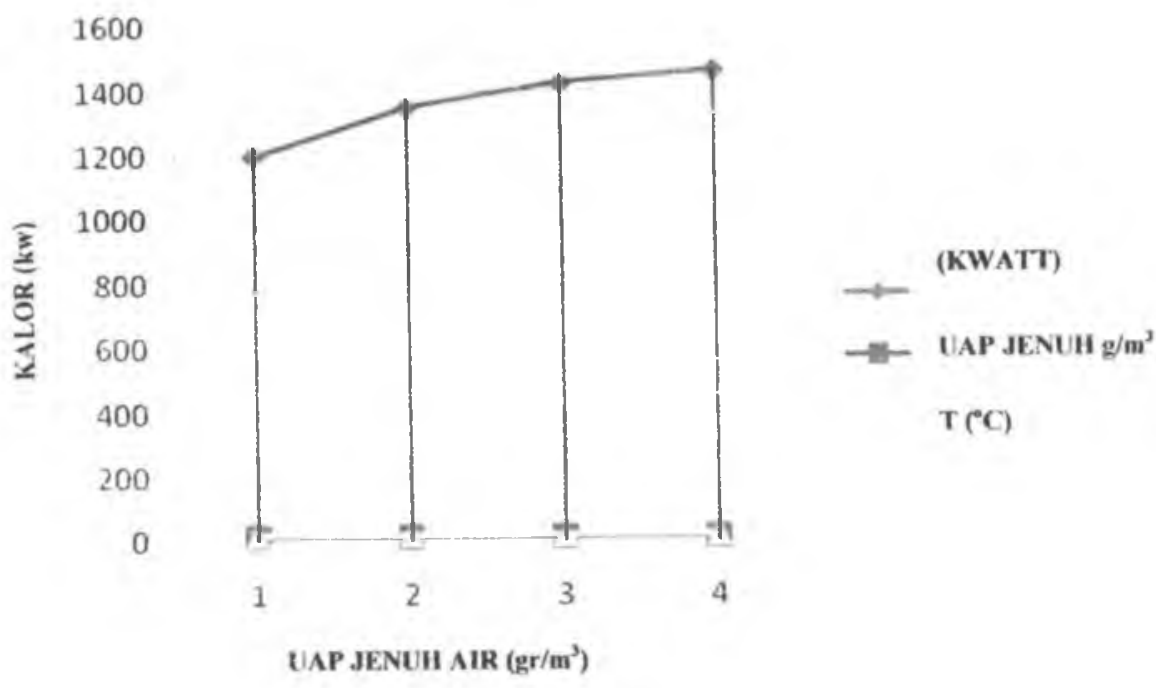

Gambar 6. hubungan antara kalor (Q) dengan uap jenuh air

Dari grafik hubungan antara kalor dengan uap jenuh air. Terlihat semakin meningkat harga kalor yang ditransfer diiringi dengan harga uap jenuh air yang sama hal ini disebabkan volume air Water Heating yang konstan (tetap). 


\section{Kesimpulan} berikut:

Berdasarkan hasil analisa penelitian maka dapat dibuat kesimpulan antara lain sebagai

1. Nilai kelembaban pengukuran lebih tinggi jika dibanding dengan nilai kelembaban teoritis, hal ini kemungkinan adanya faktor-faktor yang tidak diperhitungkan.

2. Jumlah kalor yang semakin meningkat dalam Water Heating dapat mengendalikan laju kelembaban udara.

3. Rasio kelembaban udara ada kesesuaian dengan jumlah kalor yang sama dari Water Heating, sehingga kelembaban udara di ruang operasi dapat diatur sesuai yang diinginkan.

4. Dengan harga uap jenuh air yang sama dan volume air yang konstan diiringi laju kalor yang meningkat berarti Water Heating dapat mengendalikan (mengontrol) kelembaban udara dalam ruang operasi.

\section{Daftar Pustaka}

Arismunandar, W., Saito, H., 2005, Penyegaran Udara, Cetakan ketujuh, Pradnya Paramita, Jakarta.

Arora, C.P., 1983, Refrigeration and Air Conditioning (in S1 Units), Mc Graw-Hill, New Delhi.

Carrier, 1965, Hand Book of Air Conditioning System Design, Mc Graw-Hill, New York.

Cangel, Y.A., Boles, M.A., 1989, Thermodinamics an Engineering Approach, Singapura.

Gunawan, R., 1988, Pengantar Teori Teknik Pendinginan (Refrijerasi), Departemen Pendidikan dan Kebudayaan RI, Jakarta.

Harjanto, G., 1976, Pesawat Pendingin/Pemanas, Teknik Mesin Universitas Gajah Mada, Yogyakarta.

Holman, J.P., 1980, Thermodunamics, Edisi ketiga, Mc Graw-Hill, New York.

Holman F., Jasjfi, E., 1997, Perpindahan Kalor, Edisi keenam, Erlangga, Jakarta.

Holman F., Prijono, A., 1997 Prinsip-Prinsip Perpindahan Panas, Erlangga, Jakarta.

Prasetyono, D.S., 2004, Pedoman Lengkap Teknik Memperbaiki Kulkas dan AC, Cetakan ketiga, Absolut, Yogyakarta

Putra, N., 2005, Kenaikan Koefisien Perpindahan Kalor Kondensasi Film Pada Kondensor Silinder Vertikal Dengan Nanofluida Al203-Air sebagai Fluida Pendingin, Teknik Mesin Universitas Indonesia, Jakarta.

Stoecker, W.F., Jones, J.W., 1982, Refrigeration and Air Conditioning, Edisi kedua, Mc Graw-Hill, New York.

Stoecker, W.F., 1989, Refrigerasi dan Pengkondisian Udara, Edisi kedua, Erlangga, Jakarta.

Sumanto, 2004, Dasar-Dasar Mesin Pendingin, Edisi kelima, Andi Offset, Yogyakarta. 
Wardoyo 